\title{
Additive manufacturing of thin electrolyte layers via inkjet printing of highly-stable ceramic inks
}

\author{
Zhongqi ZHU, Zhiyuan GONG, Piao QU, Ziyong LI, Sefiu Abolaji RASAKI, \\ Zhiyuan LIU, Pei WANG, Changyong LIU, Changshi LAO, Zhangwei CHEN ${ }^{*}$
}

\author{
Additive Manufacturing Institute, Shenzhen University, Shenzhen 518060, China
}

Received: July 17, 2020; Revised: October 28, 2020; Accepted: November 10, 2020

(C) The Author(s) 2020.

\begin{abstract}
Inkjet printing is a promising alternative for the fabrication of thin film components for solid oxide fuel cells (SOFCs) due to its contactless, mask free, and controllable printing process. In order to obtain satisfying electrolyte thin layer structures in anode-supported SOFCs, the preparation of suitable electrolyte ceramic inks is a key. At present, such a kind of $8 \mathrm{~mol} \% \mathrm{Y}_{2} \mathrm{O}_{3}$-stabilized $\mathrm{ZrO}_{2}$ (8YSZ) electrolyte ceramic ink with long-term stability and high solid loading (>15 wt\%) seems rare for precise inkjet printing, and a number of characterization and performance aspects of the inks, such as homogeneity, viscosity, and printability, should be studied. In this study, 8YSZ ceramic inks of varied compositions were developed for inkjet printing of SOFC ceramic electrolyte layers. The dispersing effect of two types of dispersants, i.e., polyacrylic acid ammonium $\left(\mathrm{PAANH}_{4}\right)$ and polyacrylic acid (PAA), were compared. The results show that ultrasonic dispersion treatment can help effectively disperse the ceramic particles in the inks. $\mathrm{PAANH}_{4}$ has a better dispersion effect for the inks developed in this study. The inks show excellent printable performance in the actual printing process. The stability of the ink can be maintained for a storage period of over 30 days with the help of initial ultrasonic dispersion. Finally, micron-size thin 8YSZ electrolyte films were successfully fabricated through inkjet printing and sintering, based on the as-developed high solid loading 8YSZ inks $(20 \mathrm{wt} \%)$. The films show fully dense and intact structural morphology and smooth interfacial bonding, offering an improved structural quality of electrolyte for enhanced SOFC performance.

Keywords: inkjet printing; water-based ceramic ink; solid oxide fuel cell (SOFC) electrolyte; 8YSZ; ink stability; rheological properties
\end{abstract}

\section{Introduction}

Inkjet printing is generally considered a conventional technology that involves the printing of inks onto a substrate to obtain images or texts with precise shapes and colors [1]. As a contactless manufacturing method,

\footnotetext{
* Corresponding author.
}

E-mail: chen@szu.edu.cn deposition of materials can also be easily made on target materials through inkjet printing [2]. Although other methods such as physical or chemical vapor deposition or chemical vapor deposition can also be used to produce thin film layers on substrates, inkjet printing has advantages in printing cost and is simpler and more effective than traditional processes in shape and precision control. Inkjet printing technique is used mainly based on two types of modes, namely continuous printing and drop-on-demand (DOD), with the latter 
being used more widely. Under the DOD mode, the ink is squeezed by the nozzles on the ink cartridge to from ink droplets and to achieve accurate injection of each droplet at the target position. As the water-based solvent volatiles in the spreading ink droplets, solid particles are deposited and fixed on the surface of the printing substrate. Inkjet printing is widely used for the printing and fabrication of functionally graded components [3], piezoelectric micro-devices [4], supercapacitors [5], and bendable circuits [6]. In addition to common commercial printing, inkjet printing is often used as an additive manufacturing (or three-dimensional (3D) printing) technique. By repeated deposition of ink materials layer by layer on target surface, the fabrication of 3D objects of complex structures and functionalities can be achieved $[7,8]$.

Solid oxide fuel cells (SOFCs) are a type of highly efficient and pollution free energy conversion devices with solid-state structures $[9,10]$. A planar SOFC single cell generally consists of three key layered structures, such as cathode, electrolyte, and anode layers. The electrolyte layer, different from the porous electrode layers on both sides, requires high density and low thickness in order to reduce the Ohmic loss so that the impedance can be reduced and higher ion conduction achieved, as reported by Refs. [11-14]. The unique advantages of inkjet printing technology in thin layer fabrication are expected to provide an attractive solution to achieving the desired characteristics of ceramic SOFC components [15]. A number of studies have been reported on the additive manufacturing of different SOFC components since the last decade, among which most have centered on the fabrication of the porous cathodes, such as lanthanum strontium manganite (LSM) [16,17], lanthanum strontium cobalt ferrite (LSCF) [18-20], lanthanum strontium cobalt ferrite-gadolinium doped ceria (LSCF-GDC) [21], barium trontium cobalt ferrite (BSCF) [22], etc. 8YSZ possesses excellent oxygen ion conductivity and electronic conductivity, making it a good candidate of electrolyte material for medium and high temperature SOFCs $[23,24]$. Therefore, the production of a thinner and denser $8 \mathrm{YSZ}$ ceramic electrolyte layer is one of the key factors to the improvement of the cell performance. Tomov et al. [25] reported the preparation of 5$15 \mathrm{wt} \% \mathrm{YSZ}$ inks with $2.7-4.1 \mathrm{mPa} \cdot \mathrm{s}$, which could be stably used via electromagnetic inkjet printing for up to 3 days. Stable jetting for a longer time, i.e., 4 weeks, was reported by Young et al. [26] using the prepared
YSZ ink, but the ink contained a very low solid loading (only $5.5 \mathrm{wt} \%$ ). Although limited attempts were found in the literature to fabricate thin 8YSZ electrolytes via inkjet printing, a main challenge remains to be the development of long-term stable ceramic inks with high solid loading and low viscosity suitable for inkjet printing. At present, dispersion methods are generally involved in the preparation of inks containing ceramic particles [27,28]. Small amounts of dispersants are applied in the ink system so that the ceramic particles can be fully mixed with water-based solvents and other organic additives, through mechanisms of electrostatic repulsion or spatial steric-hinderance effect. The key to the satisfying ceramic ink preparation lies in the uniform dispersion and distribution of the ceramic particles in the ink suspension and long-term stability can be achieved with minimal particle aggregation and precipitation. In addition, the prepared inks should also behave suitably to meet the requirements of the inkjet printer used. Appropriate printability such as smooth generation and jetting of ink droplets without clogging of nozzles and good spreading performance should be guaranteed [29].

In the current study, varied dispersants along with dispersion processes were used for comparison in order to prepare a suitable water-based 8 YSZ ceramic ink for inkjet printing. The properties of the as-prepared inks were characterized and evaluated. A long-term stable ink of $20 \mathrm{wt} \%$ solid loading was successfully prepared after the optimization of the formulation and dispersion effect. The subsequent inkjet printing tests approved the promising printability. Fabrication involving drying and sintering treatments of the thin electrolyte layers was conducted. The results showed that gas-tight electrolyte layers with high density, small thickness, and uniform structure and interfacial bonding were obtained, which can meet the application requirements of SOFC electrolyte layers and makes inkjet printing a promising tool for the manufacturing of SOFC thin components.

\section{Materials and methods}

\section{1 Ink formulation and preparation}

The ink compositions including ceramic particles, water-based solvents, and other additives have to be properly chosen to make the target inks environmentally friendly and easy to prepare with low cost. In this study, 
8YSZ ceramic powder with sub-micron particle size (Tianyao Co., Ltd., China) was used as the solid phase material of ink, and deionized water was chosen as the main liquid phase content. The particle size distribution can meet the specification of the nozzle size, so that the powder grinding process for size reduction could be avoided. Homogeneous particle dispersion should be reached with minimized particle agglomerations during storage and printing. An ultrasonic dispersion (UD) process was also applied to effectively break up the flocculation between ceramic particles and agglomeration of large particles that would presumably clog the printer nozzles. UD generally generates shock waves by collapsing cavitations, which then leads to collisions among the submicron particles [30,31]. The agglomerated particles are thus eroded and split by the collisions [32]. UD is considered beneficial to the reduction of ceramic slurry viscosity, sintered density, and properties of the resultant ceramics $[33,34]$. In this study, an ultrasonic disperser (Scientz- II D, Xinzhi Tech., China) was used under a mode of $570 \mathrm{~W}$ and $20 \mathrm{~Hz}$ for $30 \mathrm{~min}$.

Ink rheological behaviors such as viscosity, surface tension, and other properties could be further adjusted by adding other useful additives to meet the actual printing needs.

The powder morphology was characterized by scanning electron microscope (SEM, ProX, PhenomWorld, the Netherlands) and the particle size distribution was measured by laser particle size analyzer (Zetasizer Nano ZS90, Malvern, UK). For the choice of the dispersants, two kinds of dispersants provided by Aladdin Chemicals, China, i.e., polyacrylic acid (PAA) and polyacrylic acid ammonium $\left(\mathrm{PAANH}_{4}\right)$, were chosen for comparison of dispersion effectiveness of 8 YSZ ceramic particles in the ink systems. PAA militates mainly based on the electrostatic repulsion mechanism, whereas $\mathrm{PAANH}_{4}$ takes effect based on the combination of electrostatic repulsion and spatial steric-hinderance mechanisms. PEG-4000 (20 wt\% solution) and glycerin, both from Aladdin Chemicals, China, were used as minor additives to adjust the ink performance. The preliminary formulation of $50 \mathrm{~g}$ ink with a weight ratio of $10 \%$ is shown in Table 1 . The influence of the dispersants was compared and studied with the weight ratio $x$ set to be $0.25 \%, 0.50 \%, 1.00 \%$, $1.50 \%$, and $2.00 \%$.

\section{2 Ink characterizations}

It is necessary to determine whether the properties of
Table 1 8YSZ ceramic ink formulation at $10 \mathrm{wt} \%$ loading before the addition of minor additives

\begin{tabular}{cccc}
\hline Composition & 8 YSZ & Deionized water & Dispersant \\
\hline Weight $(\mathrm{g})$ & 5.0 & $45-50 x$ & $50 x$ \\
Weight ratio $(\mathrm{wt} \%)$ & 0.1 & $0.9-x$ & $x$ \\
\hline
\end{tabular}

the as-prepared ceramic ink conform to the requirements of the inkjet printer used $[18,35]$. The ink cartridge nozzle diameter of the Dimatix-2850 printer (FUJIFULM, USA) is $21 \mu \mathrm{m}$. According to the manufacturer specifications, optimally the average ceramic particle size in the ink should be around 1/100 of the nozzle diameter, which is $210 \mathrm{~nm}$.

Inks used for inkjet printing commonly exhibit a rheological behavior of non-Newtonian fluids [36], i.e., thinning when subjected to shear. At the same time, according to the requirements in the inkjet printer operation manual, the ink viscosity $\eta$ should be less than $20 \mathrm{mPa} \cdot \mathrm{s}$ and the surface tension of water-based inks should not exceed $60 \mathrm{mN} \cdot \mathrm{m}^{-1}$ [37]. The viscosity and surface tension of the inks at a certain shear rate were measured using a rheometer (MCR 302, Anton Paar, Austria) and an automatic surface tension tester (ZL300A, Shanghai Ben Shan Instrument Co., Ltd., China), respectively, at room temperature. Comparison of the measurement results was made to determine the suitability of the inks prior to the subsequent printing tests.

In order to characterize the stability of the prepared inks, settling experiments were first conducted. The stability of the ink system exhibits different visible settling performance, including potential sedimentation and agglomeration. The as-prepared ink was filled with $10 \mathrm{~mL}$ centrifuge tubes, and the volume of the supernatant of the ink was observed and measured for a certain amount of settling time at room temperature. The sedimentation volume ratio was calculated according to the following schematic (Fig. 1) and Eq. (1). It is evident that a larger sedimentation volume ratio suggests a lower supernatant volume ratio and a better settling behavior.

$$
f=\frac{V_{1}}{V_{0}} \times 100 \%
$$

where $V_{1}$ is the volume of the supernatant layer and $V_{0}$ is the total volume of the ink in the tube. Secondly, zeta potential, an indicator of system stability in colloidal chemistry by directly reflecting the strength of the attraction and repulsion forces between dispersed 


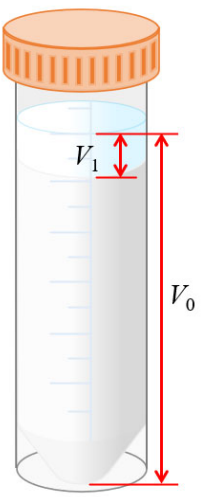

Fig. 1 Schematic of sedimentation volume fraction calculation with a supernatant layer.

particles, was measured for the as-prepared inks [38]. According to Derjaguin-Landau-Verwey-Overbeek (DLVO) theory [39], the larger the absolute value of the zeta potential, the greater the stability of the ink system can reach. Generally, when the absolute value is lower than $30 \mathrm{mV}$, the ink system is prone to particle agglomeration and sedimentation. The ink system tends to be more stable with an absolute value over $30 \mathrm{mV}$. When the absolute value is higher than $40 \mathrm{mV}$, the ink system can be considered to reach an extremely stable state [40]. The $\mathrm{pH}$ value was then measured by a $\mathrm{pH}$ meter (PB-10, Sartorius, Germany) at the same time, as the $\mathrm{pH}$ of the ink system plays a decisive role in the zeta potential value measurement. The relationship between the zeta potential and $\mathrm{pH}$ value of the ink was characterized by adjusting and measuring the zeta potential with varied $\mathrm{pH}$ of the ink based on the addition of different amounts of $0.1 \mathrm{~mol} \cdot \mathrm{L}^{-1} \mathrm{HCL}$ and $0.1 \mathrm{~mol} \cdot \mathrm{L}^{-1} \mathrm{NH}_{4} \mathrm{OH}$ (Aladdin Chemicals Co., Ltd., China). The optimal zeta potential range was then determined.

\section{3 Ink printability}

In general, preliminary calculation and evaluation can be carried out theoretically based on the ink characteristics determined to know whether the ink meets the injection requirements of the inkjet printer system. Calculations of dimensionless constants such as Reynolds' number Re and Weber's number We are usually carried out, and the calculation of these values first requires the knowledge of ink injection velocity $V$. Fromm [41] studied the droplet injection mechanism of inkjet printing and proposed the Ohnesorge number $O h$, which is independent of the injection velocity, to evaluate the printing performance of inks, as Eq. (2) showing:

$$
O h=\frac{\sqrt{W e}}{R e}=\frac{\eta}{(\gamma \rho a)^{1 / 2}}
$$

where $\eta, \gamma, \rho$, and $a$ represent the viscosity, surface tension, density of the ink, and the characteristic size of the nozzle used in the printer, respectively. The characteristic size of the nozzle is the radius of the nozzle, which is $10.5 \mu \mathrm{m}$ in this study. The printability of the ink can be described by $Z$ value for ink, where $Z=1 / O h$. It is generally accepted that when the $Z$ value is within the range of $1-10$, the ink can be considered to have high printability [42]. However, the evaluation of printability by this method is semi-empirical and sometimes an ink may have better actual printability even if its $Z$ value does not fall within this range [43].

The as-prepared ink was filled into the cartridge through a $220 \mathrm{~nm}$ aperture filter. The voltage and frequency of the printing process were properly adjusted so that formation of ink droplets with desired spherical shape and smooth injection were achieved. The actual printability was further evaluated by printing the prepared ink with pre-designed lattice dot patterns. Single line and layer units and multilayers were printed after the stable printing performance was reached.

\section{4 Electrolyte fabrication and characterizations}

The final printing purchased from SOFCMAN, China, was performed on NiO-YSZ anodes. The spread ink layers on the anode substrates still contained solidliquid mixture immediately after printing. The layers were subject to further drying and sintering, in order to fix the final shape and morphology of the layers by removing the water-based solvent and organic additives. The 8YSZ ceramic particles also experienced densification and coarsening during high-temperature sintering, so that pores were eliminated and a fully dense electrolyte film was obtained. In this study, before hightemperature sintering, the printed samples were first placed in a drying oven for $24 \mathrm{~h}$ at $50{ }^{\circ} \mathrm{C}$. In order to determine the sintering scheme of the dried sample, thermogravimetry (TG) analysis for the dried inks was tested using a TG analyzer (STA449F3 Jupiter, Netzsch, Germany), and the TG curve was obtained with a heating rate of $10{ }^{\circ} \mathrm{C} \cdot \mathrm{min}^{-1}$ to $1300{ }^{\circ} \mathrm{C}$. According to the TG result, the gasification temperature of the residual solvents and organic additives in the samples after drying and the weight loss in the heating process 
were determined, based on which a two-step sintering curve was further developed [44]. Sintering was carried out at a temperature of $1450{ }^{\circ} \mathrm{C}$ for $4 \mathrm{~h}$. The sintered samples were further characterized with X-ray diffraction (XRD, Miniflex 600, Rigaku, Japan) to study the material phase. SEM and energy disperse spectroscopy (EDS) were used to study the microstructures and the elemental distribution on the YSZ surface, the cross-sections, and the interface.

\section{Results and discussion}

\section{1 Ink formulation}

\subsubsection{Comparison of dispersant}

The experimental results after $72 \mathrm{~h}$ settling for the homogeneously mixed inks prepared with different amounts of dispersant PAA and $\mathrm{PAANH}_{4}$ before $\mathrm{pH}$ regulation are shown in Figs. 2(a) and 2(b). They are all found with very close amount of volume of supernatant. In order to distinguish the difference, the exact sedimentation volume ratios for each tube of ink were measured and plotted in Fig. 2(c) as a function of the amount of dispersant added.
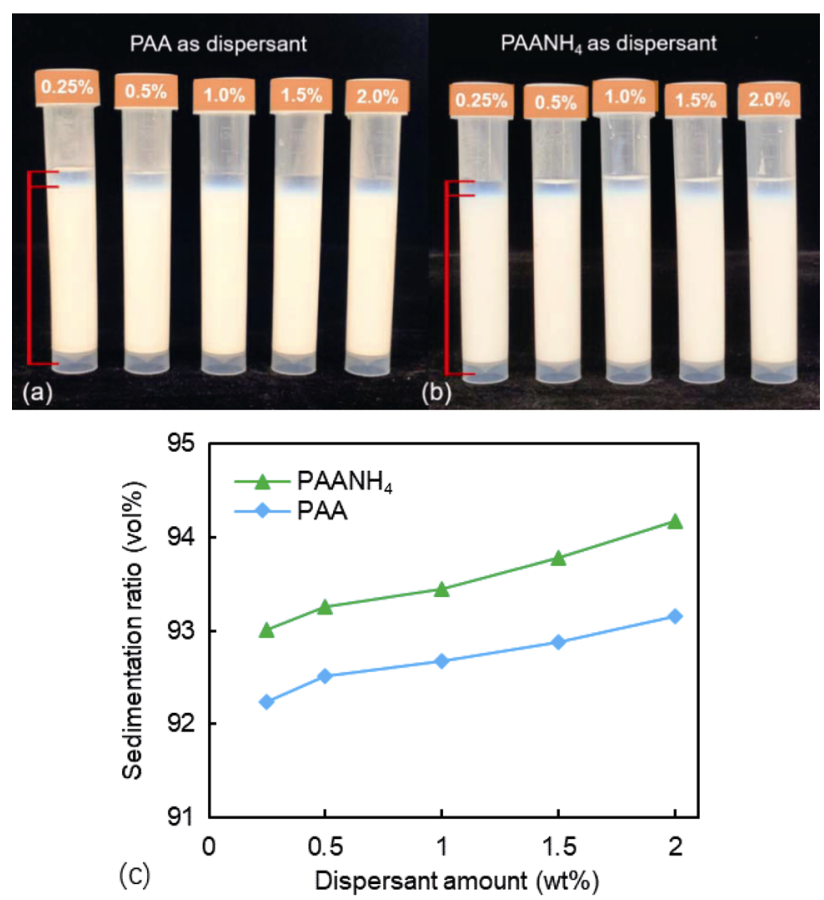

Fig. 2 Settling test after $72 \mathrm{~h}$ for the 8YSZ inks prepared with different weight ratios of (a) PAA, (b) $\mathrm{PAANH}_{4}$ as dispersants, and (c) sedimentation volume ratio as a function of the weight percent of dispersant added.
It is found that, in Fig. 2(c), for both types of dispersants, the sedimentation ratio increases with the increased amount of dispersant added. Apparently, $\mathrm{PAANH}_{4}$ has a better effect than PAA on the dispersion of the $8 \mathrm{YSZ}$ ceramic particles, although the difference is not so obvious by simple observation from Figs. 2(a) and 2(b). In addition, the sediment with $\mathrm{PAANH}_{4}$ could be quickly alleviated after sight shaking whereas in the case of the use of PAA, and the sediment was hard to separate. Therefore, in the current study, $\mathrm{PAANH}_{4}$ was chosen as a more effective dispersant for the ink.

\subsubsection{Optimization to increase solid loading}

For water-based thin inks with small solid loading, improvement in the solid content volume fraction is greatly desired, because a higher volume fraction of solid content can viably facilitate the densification of the printed layers during drying and sintering stages. However, the viscosity of the ink would also inevitably increase with the increase of the solid loading. Therefore, trade-off must be made to achieve a formulation with relatively high solid loading but small viscosity, which then fits the inkjet printing requirements [45]. The relationship between ink viscosity and the maximum solid loading is expressed via Krieger-Dougherty formula (Eq. (3)) [46], as shown below:

$$
\eta=\eta_{0}\left(1-\frac{\phi}{\phi_{\max }}\right)^{-n}
$$

where $n$ is an empirical constant, with $n=1.8 \pm 0.1, \phi$ is the solid content volume fraction in the ink suspension system, and $\phi_{\max }$ is the maximum fraction allowed. $\eta$ is the viscosity of the solid-loaded ink system and $\eta_{0}$ is without any solid content.

In this study, the mass fraction was converted into volume fraction based on the theoretical density of $8 Y S Z\left(5.9 \mathrm{~g} \cdot \mathrm{cm}^{-3}\right)$. In combination with the requirement of the printer on the viscosity range of ink from 8 to $20 \mathrm{mPa} \cdot \mathrm{s}$ and other measured data to be used in Eq. (2), the theoretical solid phase content can be obtained at most as $\phi_{\max }=23.87 \mathrm{wt} \%$. Therefore, the current ink with $10 \mathrm{wt} \%$ solid loading still remained optimizable. The effect of the addition of the dispersant $\mathrm{PAANH}_{4}$ in the $20 \mathrm{wt} \%$ 8YSZ ink is shown in Fig. 3.

In this case, the settling performance of the ink seemed even better than the aforementioned results with $10 \mathrm{wt} \%$ solid loading. The addition of $1.0 \mathrm{wt} \%$ 


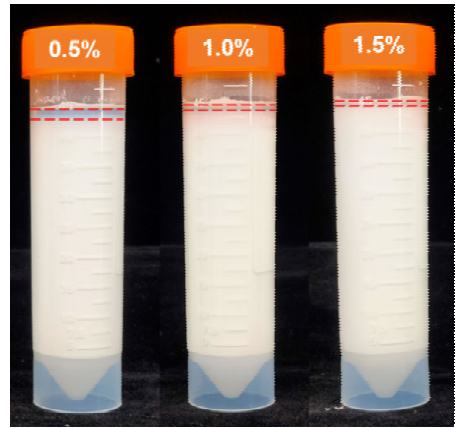

Fig. 3 Settling performance in $72 \mathrm{~h}$ of $20 \mathrm{wt} \% 8 \mathrm{YSZ}$ ceramic ink with $0.5,1.0$, and $1.5 \mathrm{wt} \% \mathrm{PAANH}_{4}$ dispersant added.

and $1.5 \mathrm{wt} \% \mathrm{PAANH}_{4}$ in the $20 \mathrm{wt} \%$ ink resulted in negligible difference. In order to minimize the use of dispersant, $1.0 \mathrm{wt} \%$ of $\mathrm{PAANH}_{4}$ was chosen. In addition, the total $50 \mathrm{~g}$ of ink also included $1 \mathrm{~g}$ of $20 \mathrm{wt} \%$ PEG-4000 solvent and $2.5 \mathrm{~g}$ glycerin. PEG4000 served to defoam the ink during generation of droplets and adjust the ink surface tension for improved spreading when printed on the substrate. Glycerin was added to slow down the drying rate during jetting to prevent clogging as a result of quick drying. The final ink is of $20 \mathrm{wt} \% 8 \mathrm{YSZ}$ solid loading. The improved ink formulation is shown in Table 2.

\section{2 Zeta potential and particle size}

The measured zeta potential of the as-prepared $20 \mathrm{wt} \%$ $8 \mathrm{YSZ}$ ceramic ink as a function of $\mathrm{pH}$ value is shown in Fig. 4 to intuitively reflect the stability of the ink. Note that the original ink had an average $\mathrm{pH}$ of 8.4.

Table 220 wt $\%$ 8YSZ ceramic ink formulation

\begin{tabular}{cccccc}
\hline \multirow{2}{*}{ Composition } & \multirow{2}{*}{ 8YSZ } & PAANH $_{4}$ & $\begin{array}{c}\text { Deionized } \\
\text { water }\end{array}$ & $\begin{array}{c}20 \mathrm{wt} \% \\
\text { PEG-4000 }\end{array}$ & Glycerin \\
\hline Weight $(\mathrm{g})$ & 10.0 & 0.5 & 36.0 & 2.5 & 1.0 \\
Weight ratio $\left(\mathrm{wt}^{2} \%\right)$ & 20.0 & 1.0 & 72.0 & 5.0 & 2.0 \\
\hline
\end{tabular}

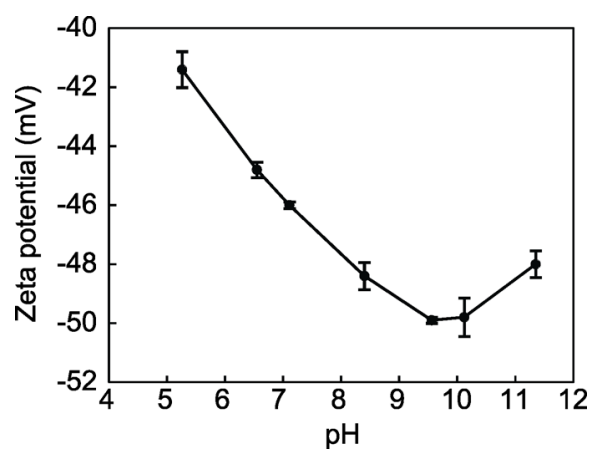

Fig. 4 Ink zeta potential as a function of $\mathrm{pH}$.
As can be seen from Fig. 4, the absolute value of zeta potential increases with the increase of $\mathrm{pH}$, that is, the stability of the ink gradually improves. The absolute value of zeta potential reaches the maximum value of $50 \mathrm{mV}$ at $\mathrm{pH} \mathrm{9-10.} \mathrm{Nevertheless,} \mathrm{all} \mathrm{the}$ absolute values of zeta potential across the different $\mathrm{pH}$ remain over $40 \mathrm{mV}$, suggesting they are all highly stable inks [40]. Such performance also well accords with the dispersing mechanism of $\mathrm{PAANH}_{4}$. In a low $\mathrm{pH}$ environment, the adsorbed $\mathrm{PAANH}_{4}$ on the ceramic particle surface cannot be dissociated and only plays the role of steric hindrance for dispersion, which is unable to maintain a relatively stable state. In contrast, at a larger $\mathrm{pH}$ not greater than 10, the repulsion between the negatively charged carboxylic groups in $\mathrm{PAANH}_{4}$ leads to dissociation and stretching out of the polymer chain, generating electrostatic force. The combined effect of steric hindrance and electrostatic force results in a more effective dispersion of the $8 Y S Z$ ceramic particles in the water-based solution [47]. Because a too low or too high $\mathrm{pH}$ should be avoided as the ink under these conditions would corrode the cartridge system including the flow channels and nozzles in the printer, therefore, a neutral ink with desired zeta potential was chosen, which in this study was at $\mathrm{pH}$ 7.11.

The sedimentation ratios and particle size distribution are plotted and compared in Fig. 5.

UD might lead to sufficient and uniform wrapping of dispersant molecular chains on the ceramic particle surface, so that the particle dispersion was further enhanced. It can be seen from Fig. 5 that the original particle size (i.e., mass-median-diameter, $D_{50}$ ) was $D_{50}=238 \mathrm{~nm}$. When the ink was prepared before the execution of UD, its particle size was $D_{50}=230 \mathrm{~nm}$, which basically met the requirements of the printer and was very close to the original size. The size distribution remained almost unchanged $\left(D_{50}=235 \mathrm{~nm}\right)$ after UD and storage for over 30 days, suggesting no agglomeration of particles and excellent long-term ink stability was obtained. The particle size distribution of the ready-toprint ink after filtration was further narrowed with $D_{50}=208 \mathrm{~nm}$, which fell right in the range of the printer requirement.

\section{3 Ink viscosity and printability}

The rheological properties of the ink also have to meet the working requirements of the inkjet printer, so that the ink can be ejected smoothly from the nozzles. A 

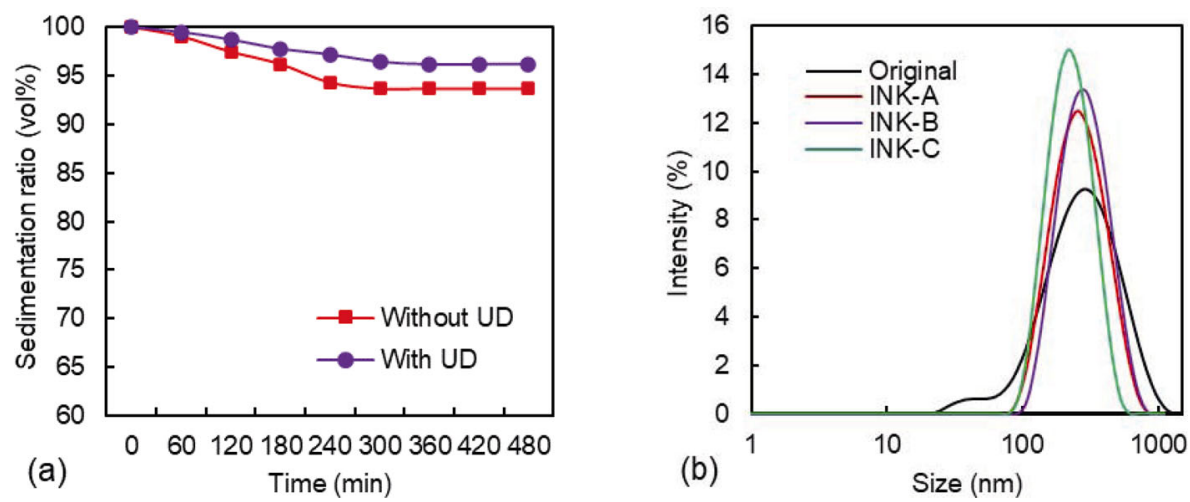

Fig. 5 (a) Sedimentation ratios of the inks without and with UD and (b) particle size distribution for the inks after different treatment. The "Original" label represents the size distribution of the as-received powder, INK-A is after preparation without before UD, INK-B is after UD and settling for over 30 days, and INK-C is the filtered ink based on INK-B.

high viscosity would lead to insufficient pressure to eject the ink, but a much lower viscosity would fail to form proper spherical droplets as the ink might flow out spontaneously with long tails or satellite droplets. Both cases would greatly affect the inkjet performance [48]. Therefore, the viscosity of the ink must be appropriately characterized and optimized. During the inkjet printing process, the ink can be subjected to a shear rate up to $1000 \mathrm{~s}^{-1}$ when the ink is ejected from the nozzle. Therefore, the $\eta$ as a function of the shear rate was measured at a shear rate range of the test was set as 0.01 to $1000 \mathrm{~s}^{-1}$, as shown in Fig. 6. From the measured data, it can be seen that the ink maintained good shear thinning behavior of non-Newtonian fluids, and the viscosity tended to level off at $1.5 \mathrm{mPa} \cdot \mathrm{s}$ after the shear rate reached $10 \mathrm{~s}^{-1}$. Prasad et al. [49] studied the shear thinning that was evident at increasing shear rates for different solid phase contents and different dispersant contents. Consistent with their results, inks with lower dispersant content converged to very low values of viscosity at higher shear rates, and Salaoru

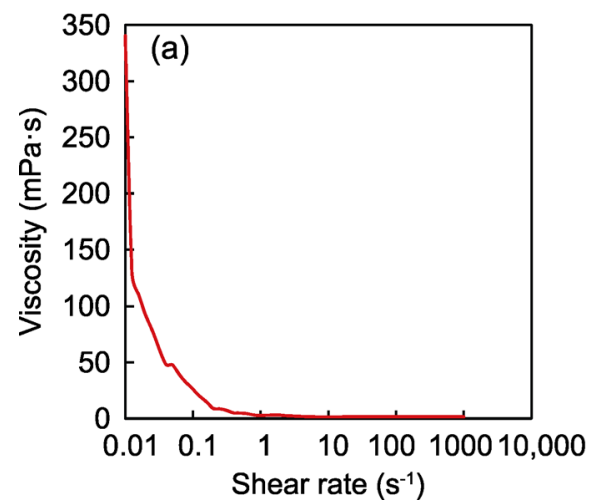

et al. [50] also showed similar rheology behavior, with viscosity stabilizing at low values at high shear rates.

In order to determine the printability of the ink according to the formula of $Z$ value calculation, i.e., Eq. (4), the surface tension and density of the ink were measured to be $\gamma=18.8 \pm 0.3 \mathrm{mN} \cdot \mathrm{m}^{-1}, \rho=1.167 \mathrm{~g} \cdot \mathrm{mL}^{-1}$, respectively, with the characteristic size of the inkjet nozzle $\alpha=10.5 \mu \mathrm{m}$.

$$
Z=\frac{(\gamma \rho \alpha)^{\frac{1}{2}}}{\eta}
$$

The $Z$ value of the current ink was derived to be $Z=$ 7.6, suggesting that the prepared ink was within the theoretical printable range. The printability was further tested by the actual printing performance. $15 \mathrm{mV}$ voltage and $1000 \mathrm{~Hz}$ frequency were applied to the printhead to conduct the printing process. The ejecting status and shape of the ink droplets were observed through the viewing camera of the printer. Before the ink was ejected from the nozzle, it was found that the ink was stably suspended in the nozzle without

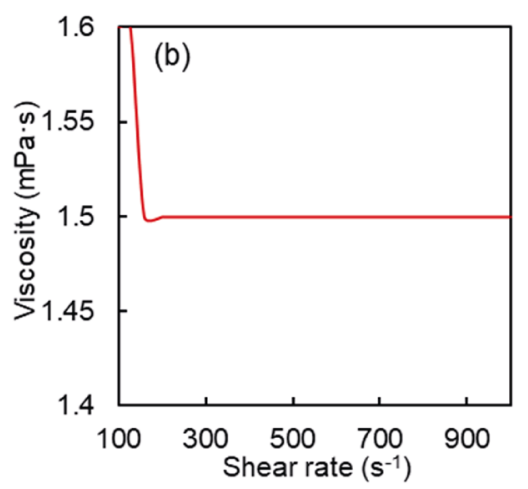

Fig. 6 Viscosity as a function of shear rate for the as-prepared $20 \mathrm{wt} \% 8 \mathrm{YSZ}$ ceramic ink in the range of (a) $0-1000$ and (b) $100-1000 \mathrm{~s}^{-1}$. 
overflowing. At the beginning of the injection, the ink was squeezed out from the nozzle and then followed the expected trajectory in good spherical shape without the generation of satellite droplets (Fig. 7), before the touching and spreading on the target substrate. The above further confirmed that the ink had great printability.

A dot array with $100 \mu \mathrm{m}$ spacing was printed to test whether the ink droplets could be evenly attached to and spread on the NiO-YSZ anode substrate surface.
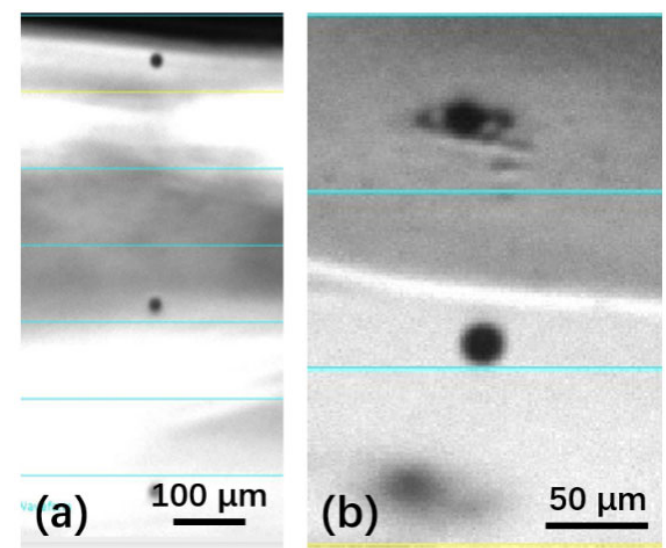

Fig. 7 Well-formed spherical shape of the inkjeted droplets: (a) low-magnification image and (b) high-magnification image.
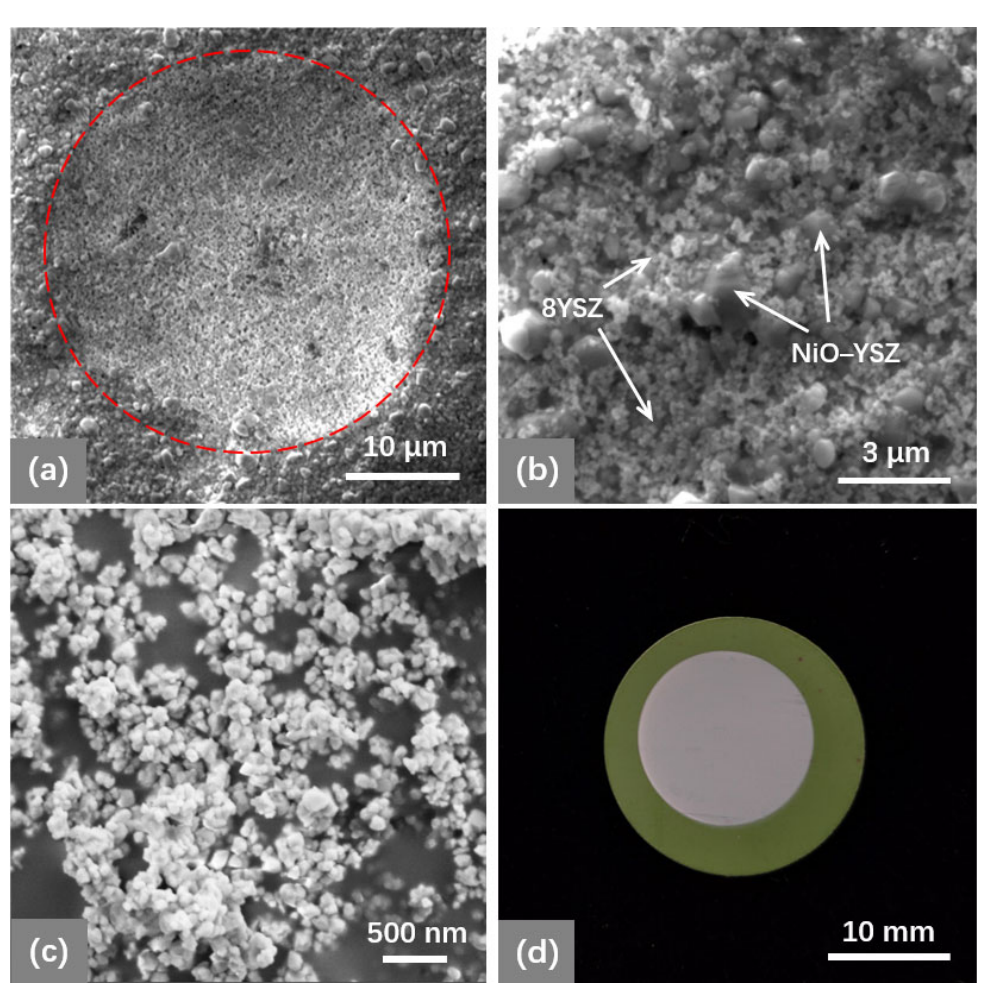

Fig. 9 (a) Ink droplet spreading on the substrate surface after drying, (b) 8YSZ particles adhering the NiO-YSZ substrate surface, (c) a closer look of the 8 YSZ particles, and (d) photograph of an electrolyte film after 10 layers of printing.

The result is shown in Fig. 8.

It can be seen from Fig. 8 that the printed lattice was neatly arranged, and each ink droplet maintained a good round-shape after spreading on the substrate. The average diameter was measured to be $31.24 \mu \mathrm{m}$. The splashes of the spread ink droplets on the substrate after oven drying were further analyzed with SEM, as shown in Fig. 9.

It is found in Fig. 9 that the ink droplets were evenly

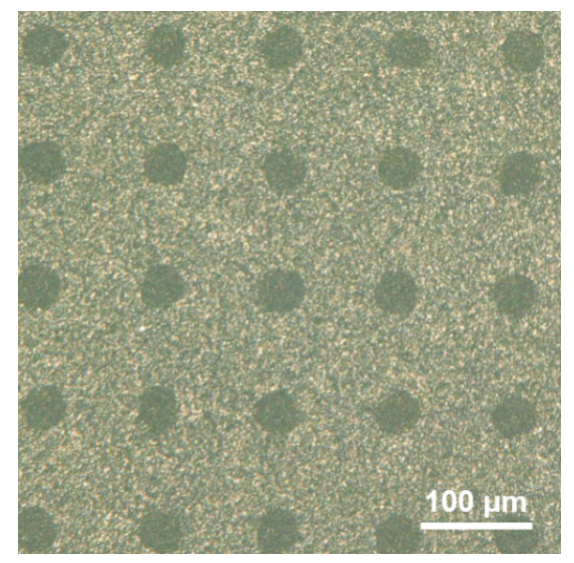

Fig. 8 Photograph of the printed dot array with $100 \mu \mathrm{m}$ spacing. 
spread on the surface of the anode substrate, which had a rough and porous surface. No coffee ring effect was observed. It is clear that the 8YSZ nanoparticles firmly attached the substrate surface but still the substrate was not fully covered by the single layer printing as quite a few NiO-YSZ grains were exposed and visible (Fig. 9(b)). Therefore, for a dense and uniform coverage of the 8YSZ ceramic ink materials, multilayer printing should be performed that the cathode and anode parts can be sufficiently detached. Figure 9(d) shows a dried electrolyte film after 10 layers of printing.

\section{4 Sintering}

After the printed parts were first air-dried at $50{ }^{\circ} \mathrm{C}$ in an oven for $24 \mathrm{~h}$, most of the deionized water in the printed films volatilized (the mass reduction was determined to be $74.9 \mathrm{wt} \%$ ), while a small amount of water, glycerin, PEG-4000, dispersant, and other nonvolatile organic additives remained unaffected, which should be fully removed by the subsequent hightemperature sintering.

The TG curve of the ink after drying shown in Fig. 10(a) indicates that the weight loss attained 15\% when the temperature reached $300{ }^{\circ} \mathrm{C}$. In this temperature range, the residual water content further was vaporized and most of the organic additives were removed. In particular, the mass loss rate was the fastest in the temperature range from 150 to $300{ }^{\circ} \mathrm{C}$, corresponding to $11.6 \%$ of weight loss. The maximum weight loss of $17.3 \%$ was found when the temperature reached $800{ }^{\circ} \mathrm{C}$. Accordingly, a low heating rate of $2.5{ }^{\circ} \mathrm{C} \cdot \mathrm{min}^{-1}$ was set for temperature up to $800{ }^{\circ} \mathrm{C}$ with a holding time of $2 \mathrm{~h}$, so that a complete removal of additives was possible. When the sintering temperature rose above $900{ }^{\circ} \mathrm{C}, 8 \mathrm{YSZ}$ began to enter the initial stage of sintering. The heating rate was further reduced between $1200{ }^{\circ} \mathrm{C}$ and the target sintering temperature of $1450{ }^{\circ} \mathrm{C}$. As a result, potential defects and internal porosities could be prevented in favor of the generation of fully dense electrolyte films. The detailed surface and cross-sectional microstructures of the prepared 10-layer 8YSZ electrolyte film following the above sintering scheme are shown in Fig. 11.

It can be seen from Fig. 11 that the film is fully dense and no porosity or cracking is found on the surface and the cross-section. The top surface is smooth and uniformly distributed with coarsened 8 YSZ grains of size ranged from 1 to $5 \mu \mathrm{m}$. Very tight bondings were

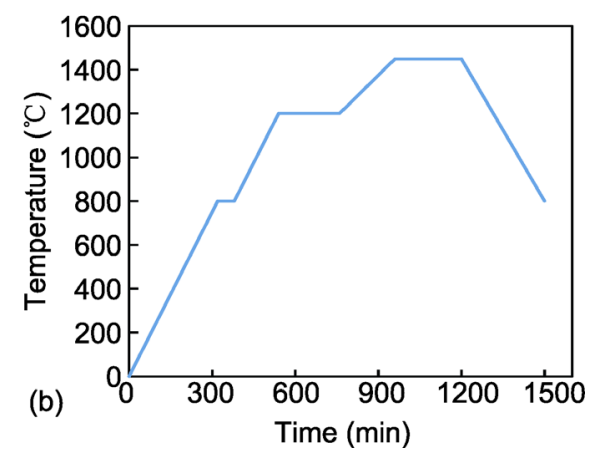

Fig. 10 (a) TG curve of the as-dried 8 YSZ ink and (b) the corresponding sintering scheme made.
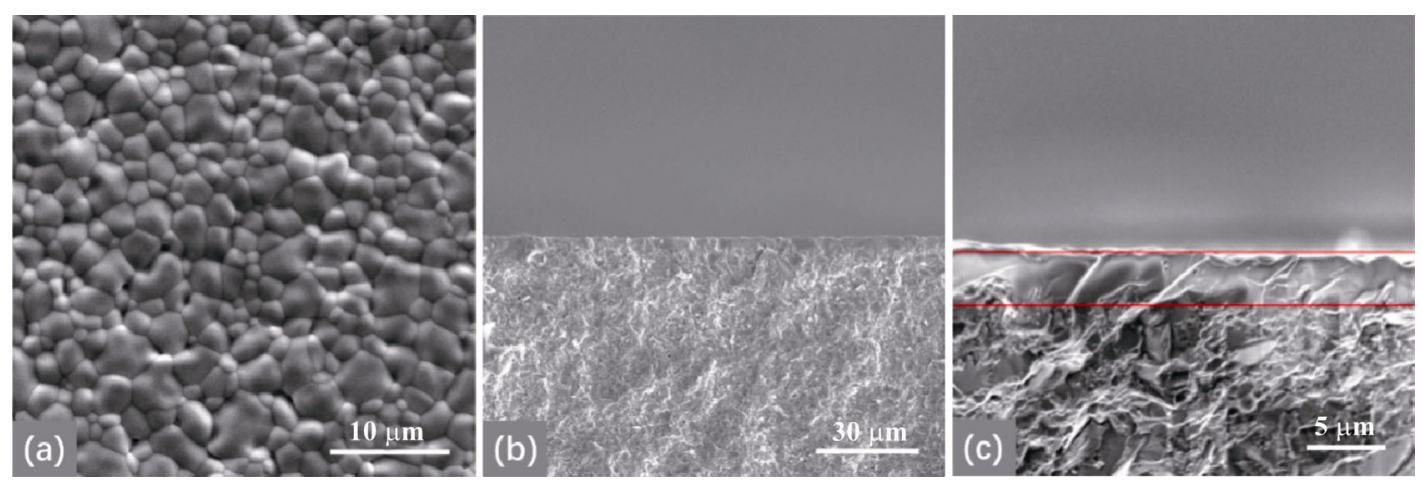

Fig. 11 Microstructures of (a) the top surface, (b) cross-section of the as-sintered 8YSZ electrolyte film printed on the anode substrate, and (c) high-magnification image of (b). 
formed between the electrolyte and the anode substrate to create complete cover over the substrate surface after sintering, resulting in a uniform average thickness measured to be $3.5 \mu \mathrm{m}$. The approximate relative density of $99.9 \% \pm 0.1 \%$ was also measured based on the grayscale image segmentation technique of the sequential SEM images of the layer cross-sections prepared. Therefore, the morphology, gas tightness, and microstructure of the inkjet-printed 8YSZ electrolyte can meet the SOFC use.

\section{5 XRD analysis}

The XRD patterns for the prepared sample are shown in Fig. 12. It shows a mixture of peaks for $8 \mathrm{YSZ}$ and NiO-YSZ, which was attributed to the very low thickness of the 8YSZ film printed. In this case, its $\mathrm{XRD}$ result was inevitably affected by the base material of the NiO-YSZ anode substrate. The original 8YSZ powder was mainly composed of monoclinic phase, whereas it can be seen in Fig. 12 that the sintered 8 YSZ mainly possessed cubic phase, along with a small amount of tetragonal and monoclinic phase. After sintering, the tetragonal phase in the 8YSZ electrolyte layer did not completely change into the monoclinic phase, indicating enhanced density to retain the tetragonal phase as the phase transition was restrained [51].

\section{6 EDS analysis}

The chemical elemental distributions of the sintered samples are shown in Fig. 13 through EDS mapping. It is found that both Figs. 13(a) and 13(b) show very uniform distribution of zirconium, yittria, and oxygen, suggesting uniform structure and surface bonding were obtained. EDS mapping of 8YSZ particles adhered on NiO-YSZ anode substrate surface shown in Fig. 13(c) suggests that there was no detectable diffusion of $\mathrm{NiO}$ toward the $8 \mathrm{YSZ}$ electrolyte layer, which is beneficial

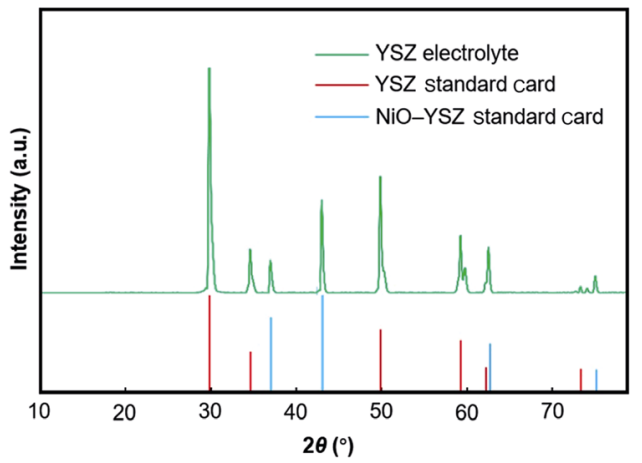

Fig. 12 XRD patterns of the as-sintered sample.
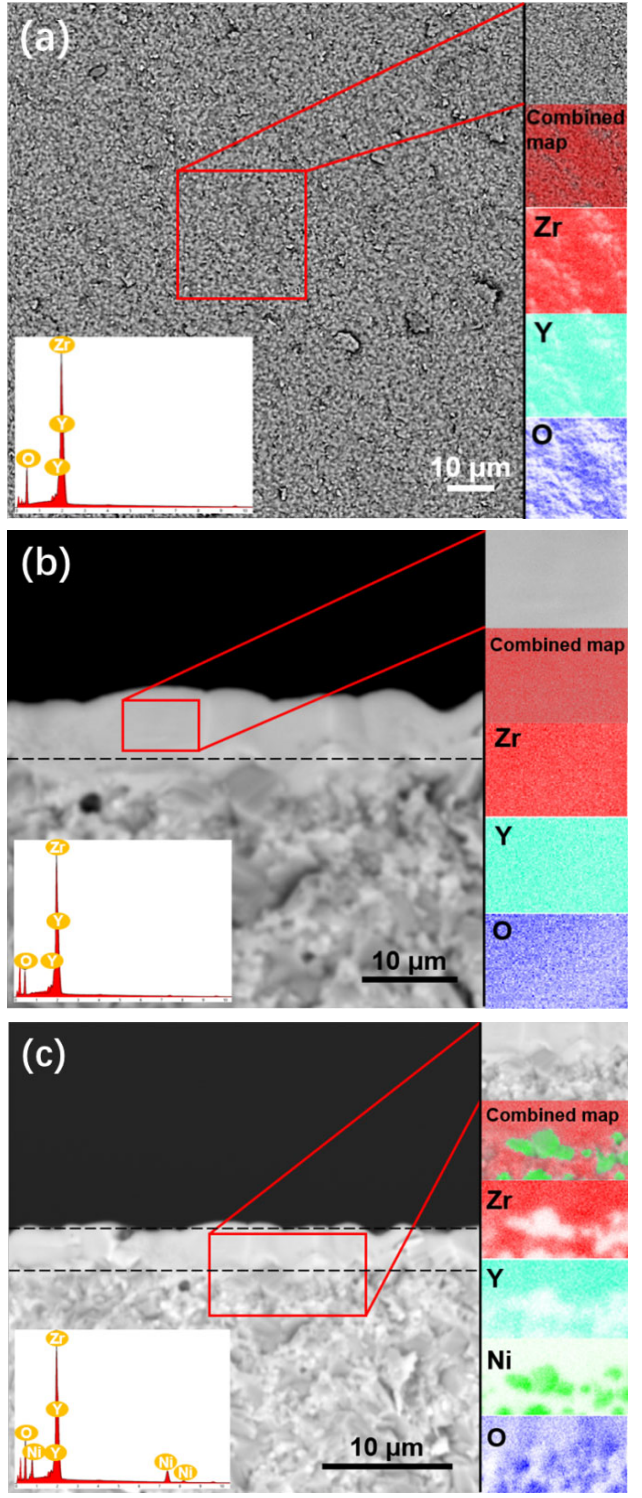

Fig. 13 EDS mapping for (a) 8YSZ surface, (b) 8YSZ cross-section, and (c) 8YSZ and NiO-YSZ interlayer cross-section.

to the functionality of the prepared components and would prevent the generation of open porosity after chemical reduction of the cell.

\section{Conclusions}

In this study, the appropriate dispersant $\left(\mathrm{PAANH}_{4}\right)$ was selected from two different dispersants, and the settling properties of the prepared inks were adjusted by adding different additives. The use of ultrasonic dispersion could further effectively help maintain the good quality of homogeneous dispersion and long-term stability of the inks for over a month of storage period. 
Characterizations of rheological properties including viscosity, surface tension, sedimentation, and zeta potential were carried out for the prepared 8YSZ ceramic ink with a solid content of $20 \mathrm{wt} \%$. The performance of the ink was evaluated, and the $Z$ value of its theoretical printability was determined. The results showed the properties of the prepared ink conformed with the inkjet printer system used in the study. A dot array was printed to further investigate the printing performance and quality of the ink. The results showed smooth ejection of spherical droplets without tails or satellites. The printed ink droplets uniformly attached and spread on the target substrate surface. The above suggests that the desired quality was achieved with the 8YSZ ceramic ink prepared in this study.

The printing of 10 layers of $8 Y S Z$ electrolyte film on the NiO-YSZ anode substrate showed promising structural characteristics. An ultrathin film with an average thickness of $3.5 \mu \mathrm{m}$ was obtained after careful studies on the printing, drying, and sintering processes. No defects such as pores or cracking were found on the surface and cross-section of the electrolyte layer, which guarantees a gas-tight electrolyte with reduced impedance might be possible. The firm bonding with no delamination of the electrolyte layer to the anode substrate also suggests excellent quality of the produced part. In summary, in this study, high solid loading (20 wt\%) 8YSZ nanoparticle inks with high dispersivity, and long-term stability and good printability were prepared. Based on the prepared ink, gas-tight thin electrolyte films on anode substrates without $\mathrm{NiO}$ diffusion during sintering were successfully fabricated via inkjet printing, ready to be used in the SOFC applications. The study suggests that inkjet printing can be a viable additive manufacturing method for the fabrication of thin ceramic component layers with great application potential.

\section{Acknowledgements}

This work is supported by the National Natural Science Foundation of China (51975384), Guangdong Basic and Applied Basic Research Foundation (2020A1515011547), Natural Science Foundation of Shenzhen (JCYJ20190808144009478), and Key-Area Research and Development Program of Guangdong Province (2020B090924003).

\section{References}

[1] Singh M, Haverinen HM, Dhagat P, et al. Inkjet printing- process and its applications. Adv Mater 2010, 22: 673-685.

[2] Chen ZW, Li ZY, Li JJ, et al. 3D printing of ceramics: A review. J Eur Ceram Soc 2019, 39: 661-687.

[3] Wang JW, Shaw LL. Fabrication of functionally graded materials via inkjet color printing. J Am Ceram Soc 2006, 89: 3285-3289.

[4] Hasegawa H. Inkjet printing and nanoscale electrocrystallization: Complete fabrication of organic microcrystals-based devices under ambient conditions. Appl Mater Today 2017, 9: 487-492.

[5] Li XY, Zhao YH, Yu J, et al. Layer by layer inkjet printing reduced graphene oxide film supported nickel cobalt layered double hydroxide as a binder-free electrode for supercapacitors. Appl Surf Sci 2020, 509: 144872.

[6] Sun JZ, Guo YZ, Cui B, et al. Inkjet printing bendable circuits based on an oil-water interface reaction. Appl Surf Sci 2018, 445: 391-397.

[7] Calvert P. Inkjet printing for materials and devices. Chem Mater 2001, 13: 3299-3305.

[8] Lejeune M, Chartier T, Dossou-Yovo C, et al. Ink-jet printing of ceramic micro-pillar arrays. $J$ Eur Ceram Soc 2009, 29: 905-911.

[9] Sharaf OZ, Orhan MF. An overview of fuel cell technology: Fundamentals and applications. Renew Sustain Energy Rev 2014, 32: 810-853.

[10] Huang ZZ, Luo LH, Liu LG, et al. Effect of $\mathrm{Al}_{2} \mathrm{O}_{3}$ addition on the non-isothermal crystallization kinetics and long-term stability of BCABS sealing glass for IT-SOFCs. $J A d v$ Ceram 2018, 7: 380-387.

[11] de Souza S, Visco SJ, de Jonghe LC. Reduced-temperature solid oxide fuel cell based on YSZ thin-film electrolyte. $J$ Electrochem Soc 1997, 144: L35-L37.

[12] Ivers-Tiffée E, Weber A, Herbstritt D. Materials and technologies for SOFC-components. J Eur Ceram Soc 2001, 21: 1805-1811.

[13] Wang CH, Worrell WL, Park S, et al. Fabrication and performance of thin-film YSZ solid oxide fuel cells. $J$ Electrochem Soc 2001, 148: A864.

[14] Leng Y. Performance evaluation of anode-supported solid oxide fuel cells with thin film YSZ electrolyte. Int J Hydrog Energy 2004, 29: 1025-1033.

[15] Calvert P. Inkjet printing for materials and devices. Chem Mater 2001, 13: 3299-3305.

[16] Sukeshini MA, Cummins R, Reitz TL, et al. Ink-jet printing: A versatile method for multilayer solid oxide fuel cells fabrication. J Am Ceram Soc 2009, 92: 2913-2919.

[17] Faino N, Rosensteel W, Gorman B, et al. Progress toward inkjet deposition of segmented-in-series solid-oxide fuel cell architectures. ECS Trans 2019, 35: 593-600.

[18] Chen ZW, Ouyang J, Liang WL, et al. Development and characterizations of novel aqueous-based LSCF suspensions for inkjet printing. Ceram Int 2018, 44: 13381-13388.

[19] Han GD, Choi HJ, Bae K, et al. Fabrication of lanthanum strontium cobalt ferrite-gadolinium-doped ceria composite cathodes using a low-price inkjet printer. ACS Appl Mater Interfaces 2017, 9: 39347-39356.

[20] Kim M, Kim DH, Han GD, et al. Lanthanum strontium cobaltite-infiltrated lanthanum strontium cobalt ferrite 
cathodes fabricated by inkjet printing for high-performance solid oxide fuel cells. J Alloys Compd 2020, 843: 155806.

[21] Yashiro N, Usui T, Kikuta K. Application of a thin intermediate cathode layer prepared by inkjet printing for SOFCs. J Eur Ceram Soc 2010, 30: 2093-2098.

[22] Li C, Shi HG, Ran R, et al. Thermal inkjet printing of thin-film electrolytes and buffering layers for solid oxide fuel cells with improved performance. Int J Hydrog Energy 2013, 38: 9310-9319.

[23] Pimenov A. Ionic conductivity and relaxations in $\mathrm{ZrO}_{2}-$ $\mathrm{Y}_{2} \mathrm{O}_{3}$ solid solutions. Solid State Ionics 1998, 109: 111118.

[24] Panthi D, Hedayat N, Du YH. Densification behavior of yttria-stabilized zirconia powders for solid oxide fuel cell electrolytes. $J$ Adv Ceram 2018, 7: 325-335.

[25] Tomov RI, Krauz M, Jewulski J, et al. Direct ceramic inkjet printing of yttria-stabilized zirconia electrolyte layers for anode-supported solid oxide fuel cells. J Power Sources 2010, 195: 7160-7167.

[26] Young D, Sukeshini AM, Cummins R, et al. Ink-jet printing of electrolyte and anode functional layer for solid oxide fuel cells. J Power Sources 2008, 184: 191-196.

[27] Tseng WJ, Chen CN. Dispersion and rheology of nickel nanoparticle inks. J Mater Sci 2006, 41: 1213-1219.

[28] Teng WD, Edirisinghe MJ, Evans JRG. Optimization of dispersion and viscosity of a ceramic jet printing ink. $J \mathrm{Am}$ Ceram Soc 2005, 80: 486-494.

[29] Bienia M, Lejeune M, Chambon M, et al. Inkjet printing of ceramic colloidal suspensions: Filament growth and breakup. Chem Eng Sci 2016, 149: 1-13.

[30] Sato K, Li JG, Kamiya H, et al. Ultrasonic dispersion of $\mathrm{TiO}_{2}$ nanoparticles in aqueous suspension. J Am Ceram Soc 2008, 91: 2481-2487.

[31] Kusters KA, Pratsinis SE, Thoma SG, et al. Energy-Size reduction laws for ultrasonic fragmentation. Powder Technol 1994, 80: 253-263.

[32] Doktycz S, Suslick K. Interparticle collisions driven by ultrasound. Science 1990, 247: 1067-1069.

[33] Suzuki TS, Sakka Y, Nakano K, et al. Effect of ultrasonication on the microstructure and tensile elongation of zirconia-dispersed alumina ceramics prepared by colloidal processing. J Am Ceram Soc 2004, 84: 2132-2134.

[34] Li CC, Li MJ, Huang YP. Dispersion of aluminum-doped zinc oxide nanopowder in non-aqueous suspensions. $\mathrm{J} \mathrm{Am}$ Ceram Soc 2017, 100: 5020-5029.

[35] Pan ZD, Wang YM, Huang HN, et al. Recent development on preparation of ceramic inks in ink-jet printing. Ceram Int 2015, 41: 12515-12528.

[36] Wang X, Carr WW, Bucknall DG, et al. High-shear-rate capillary viscometer for inkjet inks. Rev Sci Instruments 2010, 81: 065106.

[37] Driessen T, Jeurissen R. Drop formation in inkjet printing. In Fundamentals of Inkjet Printing: The Science of Inkjet and Droplets. Hoath SD, Ed. Germany: Wiley-VCH Verlag GmbH \& Co. KGaA, 2015: 93-116.

[38] Hunter RJ. Applications of the zeta potential. In Zeta Potential in Colloid Science. Hunter RJ, Ed. Amsterdam:
Elsevier, 1981: 219-257.

[39] Verwey EJW, Overbeek JTG. Theory of the stability of lyophobic colloids. J Colloid Sci 1955, 10: 224-225.

[40] Kumar A, Dixit CK. Methods for characterization of nanoparticles. In Advances in Nanomedicine for the Delivery of Therapeutic Nucleic Acids. Nimesh S, Chandra R, Gupta N, Eds. Amsterdam: Elsevier, 2017: 43-58.

[41] Fromm JE. Numerical calculation of the fluid dynamics of drop-on-demand jets. IBM J Res \& Dev 1984, 28: 322-333.

[42] Reis N, Derby B. Ink jet deposition of ceramic suspensions: Modeling and experiments of droplet formation. MRS Proc 2000, 625: 117-122.

[43] Izdebska JE, Thomas S. Printing on Polymers: Fundamentals and Applications. Amsterdam: Elsevier, 2015.

[44] Song JH, Nur HM. Defects and prevention in ceramic components fabricated by inkjet printing. J Mater Process Technol 2004, 155-156: 1286-1292.

[45] Derby B, Reis N. Inkjet printing of highly loaded particulate suspensions. MRS Bull 2003, 28: 815-818.

[46] Bergström L. Rheological properties of concentrated, nonaqueous silicon nitride suspensions. $J$ Am Ceram Soc 1996, 79: 3033-3040.

[47] Noshchenko O, Kuscer D, Mocioiu OC, et al. Effect of milling time and $\mathrm{pH}$ on the dispersibility of lead zirconate titanate in aqueous media for inkjet printing. $J$ Eur Ceram Soc 2014, 34: 297-305.

[48] Peymannia M, Soleimani-Gorgani A, Ghahari M, et al. The effect of different dispersants on the physical properties of nano $\mathrm{CoAl}_{2} \mathrm{O}_{4}$ ceramic ink-jet ink. Ceram Int 2015, 41: 9115-9121.

[49] Prasad PSRK, Reddy AV, Rajesh PK, et al. Studies on rheology of ceramic inks and spread of ink droplets for direct ceramic ink jet printing. J Mater Process Technol 2006, 176: 222-229.

[50] Salaoru I, Zhou ZX, Morris P, et al. Inkjet printing of polyvinyl alcohol multilayers for additive manufacturing applications. J Appl Polym Sci 2016, 133: 43572.

[51] Hwang KJ, Shin M, Lee MH, et al. Investigation on the phase stability of yttria-stabilized zirconia electrolytes for high-temperature electrochemical application. Ceram Int 2019, 45: 9462-9467.

Open Access This article is licensed under a Creative Commons Attribution 4.0 International License, which permits use, sharing, adaptation, distribution and reproduction in any medium or format, as long as you give appropriate credit to the original author(s) and the source, provide a link to the Creative Commons licence, and indicate if changes were made.

The images or other third party material in this article are included in the article's Creative Commons licence, unless indicated otherwise in a credit line to the material. If material is not included in the article's Creative Commons licence and your intended use is not permitted by statutory regulation or exceeds the permitted use, you will need to obtain permission directly from the copyright holder.

To view a copy of this licence, visit http://creativecommons. org/licenses/by/4.0/. 